\title{
PENGARUH IDENTITAS VISUAL, REPUTASI AKADEMIK DAN KUALITAS PELAYANAN TERHADAP TINGKAT KEPUASAN MAHASISWA UNSOED
}

\author{
Alisa Tri Nawarini ${ }^{1 *}$, Ekaningtyas Widyastuti ${ }^{1}$, Sulistyandari ${ }^{1}$ \\ ${ }^{1}$ Fakultas Ekonomi dan Bisnis, Universitas Jenderal Soedirman, Indonesia \\ *Email corresponding author: alisa.nawarini@unsoed.ac.id \\ Diterima 10/06/2020 Direvisi 26/08/2020 Diterbitkan 30/09/2020
}

\begin{abstract}
Abstrak
Penelitian ini bertujuan untuk menganalisis pengarun identitas visual, reputasi akademik dan kualitas pelayanan terhadap kepuasan mahasiswa Unsoed. Penelitian merupakan penelitian deskriptif dengan menggunakan metode survey melalui penyebaran kuesioner dalam pengumpulan datanya. Hasil penelitian menunjukkan bahwa identitas visual, reputasi akademik dan kualitas pelayanan berpengaruh positif terhadap kepuasan mahasiswa Unsoed. Berdasarkan hasil penelitian, pihak universitas perlu meningkatkan berbagai upaya dalam memelihara identitas visual, peningkatkan reputasi akademik serta peningkatan kualitas pelayanan yang diberikan demi menjaga kepuasann mahasiswa Unsoed.

Kata Kunci: Identitas Visual, Reputasi Akademik Kepuasan Mahasiswa
\end{abstract}

\begin{abstract}
This research has the aims to analyze the effect of visual identity, academic reputation and service quality on student satisfaction at Unsoed. This research is descriptive research with survey method by using questionnaire to collect the data. Research results show that visual identity, academic reputation and service quality has positive effects on student satisfaction. Based on research result, FEB should increase the way to maintaining their visual identity, increasing their academic reputation and enhancing service quality to maintaining student satisfaction
\end{abstract}

Keywords: Visual Identity, Academic Reputation, Student Satisfaction

\section{PENDAHULUAN}

Perkembangan zaman yang ada saat ini telah menuntut adanya peningkatan kualitas sumberdaya manusia sebagai salah satu input faktor produksi yang dibutuhkan dalam berbagai sektor penghidupan. Universitas merupakan institusi pendidikan tinggi yang menjadi pencetak lulusan yang diharapkan mampu memberikan input sumberdaya manusia yang berkualitas baik sebagai pelaku bisnis maupun sebagai karyawan di perusahaan.

Tingginya tuntutan akan penyediaan sumberdaya manusia yang berkualitas telah mendorong adanya permintaan yang tinggi akan adanya tenaga kerja yang profesional di bidangnya. Hal tersebut telah mendorong munculnya berbagai macam institusi pendidikan yang menawarkan berbagai macam pilihan jurusan agar dapat memenuhi kebutuhan tersebut. Unsoed sebagai institiusi pendidikan tinggi negeri di wilayah selatan Pulau Jawa telah melakukan berbagai upaya pengembangan sebagai respon atas tingkat persaingan yang meningkat di antara perguruan tinggi yang ada saat ini.. Ketatnya persaingan antar institusi pendidikan tinggi tersebut mengakibatkan institusi pendidikan tinggi saat ini perlu mencari cara yang efektif dan kreatif untuk menarik dan mempertahankan hubungan yang kuat dengan mahasiswa sebagai stakeholder utama bagi universitas.

Aspek penting yang dapat menjadi faktor penentu keberlangsungan suatu universitas adalah terciptanya kepuasan mahasiswa sebagai konsumen utama universitas. Kepuasan 
Performance. Volume 27 Nomor 2 Tahun 2020, 76-84

mahasiswa pada suatu institusi pendidikan tinggi dapat dipengaruhi antara lain oleh Identitas visual universitas (Alessandri et al, 2001), kualitas pelayanan yang diterima (Hassan et al, 2008) dan reputasi universitas (Gruber, 2010).

Identitas visual universitas merupakan salah satu aset yang bermanfaat bagi universitas dalam menghadapi persaingan antar universitas untuk mempertahankan kuantitas mahasiswa sampai dengan tingkat tertentu agar dapat terus dipandang sebagai universitas besar. Konsep identitas visual universitas merupakan suatu konsep yang merujuk pada konsep identitas perusahaan. Identitas visual universitas merupakan suatu identitas yang direncanakan secara strategis dengan tujuan untuk mendapatkan kesan positif di masyarakat. Citra positif universitas merupakan hasil dari asosiasi yang dibentuk masyarakat mengenai suatu universitas. Identitas visual universitas adalah penampakan visual/fisik universitas; berupa nama, logo, tagline, warna dan arsitektur universitas. Identitas visual universitas juga dapat berupa perilaku masyarakat yang menyangkut identitas suatu universitas (Alessandri, 2001). Bosch et al (2005) menyatakan secara lebih rinci bahwa identitas visual suatu organisasi terdiri dari semua simbol dan elemen grafis yang mampu mengekspresikan esensi organisasi. Penelitian yang dilakukan oleh Baker dan Balmer di universitas Strathclyde (1997), menunjukkan pentingnya identitas visual dalam perumusan strategi dan pemecahan masalah yang berkaitan dengan aspek fisik suatu universitas

Faktor lain yang dapat mempengaruhi kepuasan mahasiswa dalam menempuh pendidikan di universitas adalah reputasi akademik dari universitas itu sendiri. Gruber et al (2006) menyatakan bahwa reputasi akademik adalah faktor yang menentukan kepuasan mahasiswa Faktor ketiga yang berpengaruh terhadap kepuasan mahasiswa di institusi perguruan tinggi adalah kualitas layanan yang diterima oleh mahasiswa selama menempuh studi. Parasuraman et al (1990), menyimpulkan bahwa persepsi konsumen terhadap kualitas layanan yang diterima merupakan hasil perbandingan harapan dengan pengalaman pelayanan jasa yang diterima. Persepsi kualitas layanan yang diterima mahasiswa merupakan suatu bentuk interaksi mahasiswa dengan staf akademik, pengajar dan kepala departemen yang ada di universitas (Hill, 1995). Jika organisasi (dalam hal ini universitas) mampu menyediakan tingkat pelayanan yang melebihi ekspektasi konsumen, maka penilaian konsumen akan tinggi terhadap kualitas layanan yang diberikan (Zammuto, 1996). Pendapat lain dari Huang et al, 2012) menyatakan bahwa institusi dapat memperoleh kepuasan mahasiswa melalui kualitas pelayanan yang diberikan sebagai bagian dari pembentukan keunggulan kompetitif berkelanjutan.

Universitas Jenderal Sodirman (Unsoed) merupakan institusi pendidikan tinggi milik pemerintah yang terkemuka di kawasan Jawa bagian selatan. Berdasarkan data yang diperoleh dari website kemristek Dikti, saat ini Unsoed berada pada peringkat ke 23 dari seluruh universitas yang ada di Indonesia (www. Kemristekdikti.ac.id, 18 Agustus 2018). Hal ini menunjukan posisi Unsoed sebagai salah satu universitas yang banyak menjadi pilihan masyarakat dalam memilih institsi pendidikan tinggi. Berdasarkan data yang diperoleh dari situs gatra.com (30 April 2018), jumlah peminat Unsoed telah mengalami peningkatan sekitar 10\% pada tahun 2018 ini. Pada tahun 2018, jumlah pendaftar SBMPTN Unsoed sebanyak 18.607 orang, jumlah ini telah mengalami peningkatan sebesar 10\% dibandingkan jumlah pendaftar pada tahun 2017 sebanyak 16.910 orang.

Sebagai stakeholder utama universitas, kepuasan mahasiswa sebagai konsumen utama perlu menjadi prioritas Unsoed. Hal tersebut bertujuan untuk menjaga keberlangsungan Unsoed sebagai institusi pendidikan tinggi terkemuka di Indonesia serta sebagai upaya untuk mencapai visi Unsoed untuk menjadi world class Universitty.untuk mencapai tujuan tersebut, Unsoed telah melakukan berbagai strategi baik dalam aspek internal maupun eksternal untuk menjaga kepuasan mahasiswa. Untuk mengakomodasi kegiatan belajar mengajar di lingkungan Unsoed, Unsoed telah melakukan berbagai macam pengembangan aspek fisik demi tercapainya kepuasan mahasiswa. Unsoed juga menjalin kerjasama dengan berbagai pihak eksternal untuk 


\section{PERFORMANCE}

Jurnal Personalia, Financial, Operasional,

Marketing dau Sistem Informasi

Performance. Volume 27 Nomor 2 Tahun 2020, 76-84

meningkatkan reputasi akademiknya. Selain itu, peningkatan pelayanan yang diberikan kepada mahasiswa senantiasa dilakukan.

Saat ini penelitian yang meneliti tentang aspek fisik yang berpengaruh pada tingkat kepuasan mahasiswa di universitas, khususnya di Indonesia masih sangat sedikit. Oleh karena itu hasil dari penelitian ini diharapkan akan mampu memberikan kontribusi ilmiah bagi pengembangan penelitian dengan objek perguruan tinggi. Bagi Unsoed, hasil penelitian ini diharapkan dapat menjadi bahan evaluasi serta masukan bagi Unsoed khususnya untuk program pengembangan strategi pemeliharaan kepuasan mahasiswa sebagai konsumen utama universitas ke depannya.

\section{TINJAUAN PUSTAKA DAN PERUMUSAN HIPOTESIS}

\section{Identitas Visual Universitas}

Identitas visual universitas merupakan suatu konsep yang berkembang dari konsep identitas perusahaan (corporate identity). Baker dan Balmer (1997) telah memiliki data terkait dengan adanya sejumlah universitas yang mulai mengadaptasi konsep identitas perusahaan ke dalam pengembangan strategi pertumbuhan universitas. Hasil penelitian lain dari Melewar dan Akel (2005) bahka telah mampu mengembangkan model identitas perusahaan untuk sektor pendidikan. Menurut Alessandri et al (2006), identitas universitas merupakan tampilan universitas yang direncanakan secara strategis dan mengandung tujuan tertentu untuk mendapatkan citra positif di masyarakat. Identitas visual universitas terdiri dari tampilan visual universitas itu sendiri, dalam bentuk nama, logo, tagline warna, arsitektur bangunan serta perilaku universitas di masyarakat. Variabel identitas visual universitas dalam penelitian ini akan mengacu pada konsep yang dihasilkan dari penelitian Alessandri (2006). Elemen dari identitas visual perusahaan antara lain terdiri semua simbol dan elemen grafis yang mampu mengekspresikan sebuah organisasi

\section{Reputasi Akademik}

Reputasi merupakan aset tak berwujud perusahaan yang bernilai. Low dan Kalafut (2002) mendefinisikan reputasi sebagai persepsi organisasi oleh berbagai macam orang. Definisi yang lebih spesifik mengenai reputasi perusahaan dinyatakan oleh Gotsi dan Wilson (2001). Gotsi dan Wilson (2001) mendefinisikan reputasi perusahaan sebagai evaluasi seluruh stakeholder terhadap perusahaan seiring berjalannya waktu. Reputasi dibangun seiring berjalannya waktu melalui interaksi sosial dan komunikasi publik serta pembangunan reputasi sendiri memerlukan waktu yang sangat panjang.

Dari konsep reputasi perusahaan di atas, dapat disimpulkan bahwa reputasi universitas terbentuk dari pengalaman stakeholder secara langsung maupun tidak langsung dengan universitas dan informasi yang diperoleh stakeholder melalui berbagai saluran komunikasi dan simbol-simbol(Alessandri et al, 2006). Menurut Alessandri et al (2006), konsep reputasi universitas terdiri dari tiga dimensi, yaitu kualitas kinerja akademik universitas, kualitas dari kinerja eksternal universitas dan ikatan emosional yang dimiliki mahasiswa dengan universitas.

\section{Kualitas Pelayanan}

Menurut Lupioyadi (2008 : 181), kualitas pelayanan adalah sebuah faktor penentu kesuksesan dan kualitas dari suatu perusahaan. Menurut Nasution (2004:27), kualitas pelayanan adalah tingkat kinerja yang diharapkan dan kendali atas kualitas untuk memenuhi kebutuhan konsumen. Parasuraman et al (1985) mendefinisikan kualitas pelayanan sebagai perbedaan antara kenyataan dan harapan konsumen atas jasa yang diterima. Indikator dari kualitas pelayanan menurut Zeithmal et al, 2009) :Tangibility (kondisi fisik dari penyedia jasa yang terdiri dari fasilitas fisik, peralatan, penampilan karyawan dan peralatan komunikasi yang digunakan) ; 


\section{PERFORMANCE}

Jurnal Personalia, Financial, Operasional,

Marketing dau Sistem Informasi

Performance. Volume 27 Nomor 2 Tahun 2020, 76-84

Reliability (kemampuan untuk memberkan jasa secara akurat dan meyakinkan) ; Responsiveness (inisiatif dari karyawan untuk membantu konsumen dan memberikan jasa sesuai dengan kebutuhan); Assurance (pengetahuan, kemampuan, kesopanan karyawan dalam memberikan pelayanan); Emphaty (perhatian individual yang diberikan oleh penyedia jasa kepada konsumennya)

\section{Kepuasan Mahasiswa}

Kepuasan adalah suatu perbandingan antara harapan dan pengalaman yang memberikan suatu evaluasi setelah melakukan konsumsi suatu produk/jasa J.C.Castro et.al (2017). Sedangkan menurut Tjiptono (2012:24) kepuasan konsumen adalah perasaaan seseorang setelah membandingkan kinerja dengan harapan

\section{Pengembangan Hipotesis}

Melawar dan Akel (2005) dalam penelitiannya berpendapat bahwa identitas visual akan dapat meningkatkan kesadaran publik akan kapabilitas, kekuatan, produk, layanan dan eksklusifitas suatu institusi . desain logo, pengaplikasian warna, simbol, arsitektur gedung, penggunaan nama serta desain slogan dapat digunakan untuk membangun citra bagi institusi sebagaimana dipersepsikan oleh konsumen. Hasil penelitian Melawar dan Akel (2005) dan MarzoNavarro et al (2005) menunjukan adanya pengaruh positif identitas visual universitas terhadap kepuasan konsumen. Berdasarkan uraian di atas, hipotesis pertama dalam penelitian ini dapat dirumuskan sebagai berikut:

\section{$\mathrm{H} 1$ : Identitas visual universitas berpengaruh positif terhadap kepuasan mahasiswa.}

Reputasi akademik yang dimiliki oleh suatu universitas merupakan salah satu prediktor kepuasan mahasiswa. Hal tersebut ditunjukkan oleh hasil penelitian Gruber et al (2010) yang melakukan penelitian terhadap jasa pendidikan tinggi di Jerman. Salah satu hasil penelitiannya menunjukkan adanya pengaruh positif antara reputasi akademik dengan kepuasan mahasiswa. Penelitian lain dari Kao (2007) juga menunjukkan adanya pengaruh positif dari reputasi akademik terhadap kepuasan mahasiswa. Berdasarkan uraian di atas, hipotesis kedua dalam penelitian ini dapat dirumuskan sebagai berikut :

\section{$\mathrm{H} 2$ : Reputasi akademik universitas berpengaruh positif terhadap kepuasan mahasiswa.}

Salah satu tujuan universitas adalah memberikan pelayanan terbaik bagi mahasiswa demi tercapainya keberlangsungan universitas. Menurut Russel (2005), salah satu tujuan utama institusi Pendidikan tinggi adalah menyediakan pelayanan yang prima kepada mahasiswa. Penelitian yang dilakukan oleh Poh et al (2006) dan Abd Rahman et al (2008) menemukan adanya pengaruh positif dari kualitas pelayanan yang diberikan dengan tingkat kepuasan mahasiswa. Penelitian lain dari Soutar et al (1996) juga memerikan hasil serupa. Berdasarkan uraian di atas, maka hipotesis ketiga dalam penelitian ini dapat dirumuskan sebagai berikut :

\section{H3 : Kualitas pelayanan universitas berpengaruh positif terhadap kepuasan mahasiswa}

\section{METODE PENELITIAN}

Penelitian ini merupakan penelitian deskriptif dengan menggunakan metode survey melalui kuesioner dalam pengumpulan datanya. Metode pengambilan sampel yang digunkan adalah Stratified Sampling Method dengan populasi mahasiswa aktif Unsoed. Jawaban responden akan diukur dengan menggunakan skala Likert, sedangkan untuk menguji pengaruh masing-masing variabel independen terhadap dependennya akan digunakan metode analisis regresi berganda. 
Performance. Volume 27 Nomor 2 Tahun 2020, 76-84

\section{HASIL DAN PEMBAHASAN}

Berdasarkan data https://forlap.ristekdikti.go.id/perguruantinggi/detail, (18 November 2018) jumlah mahasiswa Unsoed yang aktif pada semester gasal T.A 2017/2018 sebanyak 21.799 orang mahasiswa. Tekhnik pengambilan sampel dilakukan dengan metode stratified sampling method agar jumlah sampel yang diambil dapat mewakili mahasiswa seluruh fakultas yang ada di Unsoed. Dengan menggunakan rumus Slovin diperoleh hasil jumlah sampel minimal yang diperlukan dalam penelitian ini adalah sebanyak 393 orang mahasiswa Unsoed dengan rincian sebagai berikut :

Tabel 1. Responden Penelitian

\begin{tabular}{lrc}
\hline \multicolumn{1}{c}{ Fakultas } & $\begin{array}{c}\text { Jumlah Mahasiswa Aktif } \\
\text { (orang) }\end{array}$ & $\begin{array}{c}\text { Jumlah } \\
\text { Sampel } \\
\text { (orang) }\end{array}$ \\
\hline Pertanian & 2.884 & 52 \\
Biologi & 1.045 & 19 \\
Fakultas Ekonomi dan Bisnis & 3.769 & 68 \\
Petertnakan & 1.540 & 28 \\
Hukum & 2.209 & 40 \\
FISIP & 2.363 & 43 \\
Kedokteran & 1.102 & 20 \\
Tekhnik & 1.466 & 26 \\
FIK & 2.063 & 37 \\
IImu Budaya & 1.594 & 29 \\
MIPA & 930 & 17 \\
Perikanan dan IImu Kelautan & 834 & 15 \\
\hline Jumlah & 21.799 & 393 \\
\hline
\end{tabular}

Berdasarkan hasil analisis data yang telah dilakukan, hasil pengujian hipotesis penelitiannya adalah sebagai berikut :

\section{Karakteristik Demografis Responden}

Data terkait dengan karakteristik demografis responden mahasiswa yang menjadi responden dalam penelitian ini dapat dilihat pada tabel di bawah ini:

Tabel 2. Karakteristik Demografis Responden

\begin{tabular}{clr}
\hline Karakteristik & \multicolumn{1}{c}{ Kategori } & Jumlah Responden (orang) \\
\hline Jenis Kelamin & Perempuan & 241 \\
& Laki-laki & 152 \\
\hline Daerah Asal & Jawa Tengah & 247 \\
& DI Yogyakarta & 7 \\
& Jawa Barat & 46 \\
& JABOTABEK & 72 \\
& Jawa Timur & 7 \\
& Sumatra & 5 \\
& Kalimantan & 6 \\
& Lainnya & 3 \\
\hline UKT per semester & $<$ Rp 1.000.000 & 70 \\
& Rp 1.000.000-Rp 2.000.000 & 43 \\
& $>$ Rp 2.000.000-Rp 3.000.000 & 94 \\
& $>$ Rp 3.000.000-Rp 4.000.000 & 93 \\
& $>$ Rp 4.000.000-Rp 5.000.000 & 19 \\
& $>$ Rp 5.000.000 & 74 \\
\hline
\end{tabular}


Jurnal Personalia, Financial, Operasional,

Marketing dau Sistem Informasi

Performance. Volume 27 Nomor 2 Tahun 2020, 76-84

\section{Koefisien Determinasi $\left(R^{2}\right)$}

Nilai koefisien determinasi menunjukkan besarnya variasi variabel dependen yang dijelaskan oleh variasi-variasi variabel independen. Semakin besar nilai $R^{2}$ berarti semakin besar variasi variabel dependen yang dapat dijelaskan oleh variasi variabel-variabel independen. Sebaliknya, semakin kecil nilai $R^{2}$ berarti semakin kecil variasi variabel dependen yang dapat dijelaskan oleh variasi variabel independen.

Tabel 3. Model Summary

\begin{tabular}{ccccc}
\hline Model & $\mathrm{R}$ & R Square & Adjusted R Square & $\begin{array}{c}\text { Std. Error of the } \\
\text { Estimate }\end{array}$ \\
\hline 1 & $.637 a$ & .406 & .402 & .52588 \\
\hline
\end{tabular}

a. Predictors: (Constant), Kepuasan_layanan, Reputasi_akademik, Identitas_visual

Nilai adjusted $R^{2}$ sebesar $0,402(40,2 \%)$ menunjukkan bahwa variasi variabel dependen dapat dijelaskan oleh variasi variabel-vatiabel independen sebesar $40,2 \%$ saja. Sedangkan sisanya dijelaskan oleh variabel-variabel lain yang tidak diteliti dalam penelitian ini.

\section{Uji Signifikan Simultan (Uji Statistik F)}

Uji $\mathrm{F}$ digunakan untuk menguji ketepatan model atau goodness of fit. Untuk dapat menyimpulkan apakah model termasuk kategori cocok (fit) atau tidak. Hasil uji F dapat dilihat pada tabel berikut ini :

Tabel 4. ANOVA ${ }^{b}$

\begin{tabular}{|c|c|c|c|c|c|c|}
\hline & Model & Sum of Squares & df & Mean Square & $\mathrm{F}$ & Sig. \\
\hline \multirow[t]{3}{*}{1} & Regression & 68.021 & 3 & 22.674 & 63.397 & $.000^{\mathrm{a}}$ \\
\hline & Residual & 139.482 & 390 & .358 & & \\
\hline & Total & 207.503 & 393 & & & \\
\hline
\end{tabular}

a. Predictors: (Constant), Kepuasan_layanan, Reputasi_akademik, Identitas_visual

b. Dependent Variable: Kepuasan_mahasiswa

Dari tabel di atas dapat dilihat nilai sig. Sebesar 0,000 lebih kecil dari a 0,05. Sehingga dengan demikian modekl penelitian ini dapat dinyatakan memenuhi kriteria (fit).

\section{Analisis Regresi Berganda}

Pengujian hipotesis penelitian akan dilakukan dengan metode analisis regresi berganda. Analisis regresi berganda digunakan untuk mengetahui pengaruh parsial variabel independen terhadap variabel dependennya.

Tabel 5. Hasil Analisis Regresi Berganda

Coefficients $^{\mathrm{a}}$

\begin{tabular}{|c|c|c|c|c|c|c|}
\hline \multirow{2}{*}{\multicolumn{2}{|c|}{ Model }} & \multicolumn{2}{|c|}{ Unstandardized Coefficients } & \multirow{2}{*}{$\begin{array}{c}\begin{array}{c}\text { Standardized } \\
\text { Coefficients }\end{array} \\
\text { Beta }\end{array}$} & \multirow[b]{2}{*}{$\mathrm{t}$} & \multirow[b]{2}{*}{ Sig. } \\
\hline & & B & Std. Error & & & \\
\hline \multirow[t]{4}{*}{1} & (Constant) & .313 & .207 & & 1.515 & .131 \\
\hline & Identitas_visual & .169 & .071 & .124 & 2.384 & .018 \\
\hline & Reputasi_akademik & .351 & .071 & .245 & 4.961 & .000 \\
\hline & Kepuasan_layanan & .416 & .065 & .326 & 6.364 & .000 \\
\hline
\end{tabular}

a. Dependent Variable: Kepuasan_mahasiswa 
Performance. Volume 27 Nomor 2 Tahun 2020, 76-84

Hasil analisis regresi berganda di atas digunakan untuk menjelaskan pengaruh parsial dari variabel identitas visual, reputasi akademik dan kepuasan layanan terhadap kepuasan mahasiswa Unsoed. Hasil regresi di atas dapat dijelaskan sebagai berikut :

\section{Pengaruh Identitas Visual Terhadap Kepuasan Mahasiswa}

Berdasarkan analisis data dengan menggunakan SPSS, diperoleh nilai t hitung sebesar 2,384. Nilai t hitung ini lebih besar dari nilai t tabel $(1,645)$, sehingga dengan demikian hipotesis pertama dinyatakan diterima. Hasil analisis data menunjukkan indentitas visual universitas yang dimiliki Unsoed memiliki pengaruh positif terhadap tingkat kepuasan mahasiswa.

Identitas visual terdiri dari berbagai aspek fisik universitas yang dapat dilihat oleh mahasiswa. Identitas visual yang dimiliki oleh Unsoed terlihat dari banyaknya fasilitas yang tersedia untuk menunjang berbagai kegiatan mahasiswa. Berdasarkan jawaban responden, Unsoed dianggap telah memiliki berbagai desain arsitektur gedung baru yang berkesan modern dan megah, memiliki ruang perkuliahan yang cukup nyaman, memiliki tagline yang inspiratif serta memiliki fasilitas pendukung perkuliahan yang lengkap. Ditinjau dari aspek relasional, universitas dianggap telah berhasil menjalin hubugan baik dengan mahasiswa serta mampu menjaga hubungan baik antar berbagai elemen kampus. Lengkapnya fasilitas pendukung yang antara lain tercermin dari lengkapnya fasilitas perpustakaan, laboratorium dan sarana olahraga mampu mempengaruhi tingkat kepuasan mahasiswa selama mengenyam pendidikan di Unsoed.

Hasil penelitian ini menunjukaan keberhasilan Unsoed dalam meningkatkan berbagai aspek identitas visual yang dimilikinya dalam usahanya untuk memuaskan mahasiswa. Pembangunan infrastruktur dan sarana penunjang perkuliahan selalu dilakukan Unsoed dalam upayanya untuk menjadi salah satu lembaga perguruan tinggi terkemuka di dunia. Hasil penelitian ini menunjang hasil penelitian Melawar dan Akel (2005) dan Marzo-Navarro et al (2005) yang menunjukan adanya pengaruh positif identitas visual universitas terhadap kepuasan konsumen

\section{Pengaruh Reputasi Akademik terhadap Kepuasan Mahasiswa}

Berdasarkan analisis data dengan menggunakan SPSS, diperoleh nilai t hitung sebesar 4,961. Nilai t hitung ini lebih besar dari nilai t tabel $(1,645)$,sehingga dengan demikian hipotesis kedua dapat dinyatakan diterima. Hasil analisis data menunjukkan reputasi akademi yang dimiliki Unsoed memiliki pengaruh positif terhadap tingkat kepuasan mahasiswa.

Reputasi akademik Unsoed terbentuk dari kualitas kinerja akademik universitas, kualitas dari kinerja eksternal universitas dan besarnya ikatan emosional yang dimiliki mahasiswa dengan universitas. Dengan terciptanya reputasi akademik yang baik maka kepuasan mahasiswa dalam menjalani pendidikan di Unsoed juga akan terjaga dengan baik. Hasil penelitian ini menunjang penelitian dari Kao (2007) dan Gruber et al (2010) yang menunjukkan adanya pengaruh positif antara reputasi akademik dengan kepuasan mahasiswa. Penelitian lain dari Kao (2007) juga menunjukkan adanya pengaruh positif dari reputasi akademik terhadap kepuasan mahasiswa.

\section{Pengaruh Kualitas Pelayanan terhadap Kepuasan Mahasiswa}

Nilai t hitung sebesar 6,364 lebih besar dari nilai t tabel $(1,645)$, sehingga dengan demikian hipotesis ketiga yang menyatakan terdapat pengaruh positif antara kualitas pelayanan terhadap kepuasan mahasiswa dapat dinyatakan diterima. Kualitas pelayanan merupakan faktor utama yang menjadi penentu kepuasan mahasiswa sebagai konsumen universitas. Kualitas layanan yang diberikan pihak universitas terhadap mahasiswa dapat terlihat dari aspek kesopanan karyawan maupun dosen dalam memberikan pelayanan. 
Performance. Volume 27 Nomor 2 Tahun 2020, 76-84

\section{KESIMPULAN}

Hasil penelitian menunjukan terdapat pengaruh positif variabel identitas visual, reputasi akademik dan kualitas pelayanan terhadap kepuasan mahasiswa di Universitas Jenderal Soedirman. Dalam menjaga tingkat kepuasan mahasiswa, Unsoed perlu meningkatkan fasilitas fisik pendukung kegiatan pembelajaran sebagai identitas visual bagi Unsoed. Penambahan fasilitas serta peremajaan gedung yang dimiliki dapat dilakukan untuk memberikan kenyamanan bagi mahasiswa dalam menempuh pendidikan di Unsoed. Reputasi akademik Unsoed dapat ditingkatkan dengan mengembangkan jalinan kerjasama yang baik dengan pihak eksternal, baik dengan pihak institusi pendidikan lainnya (baik dalam ataupun luar negeri), pihak pemerintah dan dinas terkait serta dengan media massa. Reputasi akademik yang terjaga baik akan mampu meningkatkan rasa bangga sekaligus juga kepuasan mahasiswa. Dalam melayani kepentingan mahasiswa, tenaga pendidik maupun tenaga kependidikan Unsoed perlu menempatkan mahasiswa sebagai konsumen utama. Unsoed dapat memberikan pelatihan bagi tenaga kependidikan untuk menjaga dan meningkatkan kualitas pelayanan yang diberikan kepada mahasiswa.

Penelitian yang dilakukan masih memiliki keterbatasan, diantaranya adalah dengan nilai adjusted $R^{2}$ sebesar 40,2\% yang menunjukkan masih kecilnya kontribusi pengaruh variabel independen terhadap variabel dependennya. Untuk penelitian selanjutnya, peneliti dapat menambahkan variabel lainnya seperti biaya kuliah, persepsi kualitas akademik sebagai variabel independen dan variabel word of mouth sebagai variabel dependennya.

\section{DAFTAR PUSTAKA}

Alessandri, S.W. (2001). Modeling Corporate Identity : A Concept Explication And Theoritical Explanation. Corporate Communication : An International Journal

Alessandri, S.W, Sung Un Yang, Denis F Kinsey. (2006). An Integrative Approach to University Visual Identity and Reputation. Corporate Reputation Review, p. 258-270

Baker, MJ dan JMT Balmer. (1997). Visual identity : Trappings or Substance. European Journal of marketing, 31: p (5/6), p: 366-382

Gruber, TS,Fub R Voss dan M Glaser Zikuda. (2010). Examining Student Satuisfaction With Higher Education Services : Using A New Measurement Tool. International Journal Of Public Sector Management. P.105-123

Melewar, T.C dan S Akel. (2005). The Role Of Corporate Identity In The Higher Education Sector : A Case Study. Corporate Communications : An International Journal p: 41-57

Marzo-Navarro,M, M Pedraja-Iglesias dan M.P Rivera Torres. (2005). Measuring Customer Satisfaction In Summer Courses. Quality Assurance In Education, p: 53-65

Parasuraman, A., Valarie Zeithaml, dan Leonard Berry. (1985). A Conceptual Model Of Service Quality And Its Implications For Future Research, journal of Marketing (Fall) , 41-50

Poh, JU Peng, Abu Samah dan Ainon Jauhariah. (2006). Measuring Student Satisfaction For Quality Education In A Learning University, Unitar E Journal 2(1), 11-21

Tjiptono, Fandy. (2005). Service, Quality and Satisfaction, edisi pertama, Yogyakarta: Andi Offset 


\section{PERFORMANCE}

Jumal Personalia, Financial, Operasional

Performance. Volume 27 Nomor 2 Tahun 2020, 76-84

Van den osch, A.L,M,M.D.T,De Jong dan W.J.L Elving. (2005). How Corporate Visual Identity Supports Reputation, Corporate Communications : An International Journal 10(1), p:108-116

Zammuto,R.F,Keaveney,S.M dan O'Connor, E.J. (1996). Rethinking Students Services : Assesing And Improving Service Quality, Journal Of Marketing In Higher Education,7(1),45-69 